\title{
Analysis of flood events in Slovenian streams
}

\author{
Nejc Bezak, Alja Horvat, Mojca Šraj* \\ University of Ljubljana, Faculty of Civil and Geodetic Engineering, Jamova 2, SI-1000 Ljubljana, Slovenia. \\ ${ }^{*}$ Corresponding author. Tel.: +386142540 52. Fax:+386125198 97. E-mail: mojca.sraj@fgg.uni-lj.si
}

\begin{abstract}
The detailed analysis of individual flood event elements, including peak discharge $(Q)$, flood event volume $(V)$, and flood event duration $(D)$, is an important step for improving our understanding of complex hydrological processes. More than 2,500 flood events were defined based on the annual maximum (AM) peak discharge from 50 Slovenian gauging stations with catchment areas of between 10 and $10,000 \mathrm{~km}^{2}$. After baseflow separation, the stations were clustered into homogeneous groups and the relationships between the flood event elements and several catchment characteristics were assessed. Different types of flood events were characteristic of different groups. The flashiness of the stream is significantly connected with mean annual precipitation and location of the station. The results indicate that some climatic factors like mean annual precipitation and catchment related attributes as for example catchment area have notable influence on the flood event elements. When assessing the dependency between the pairs of flood event elements $(Q, V, D)$, the highest correlation coefficients were obtained for the $Q-V$ pair. The smallest correlations or no correlations were observed between the $Q$ and $D$ variables.
\end{abstract}

Keywords: Baseflow separation; Catchment characteristics; Flood event; Comparative hydrology.

\section{INTRODUCTION}

The flood event volume $(V)$ and duration $(D)$ are important factors for several practical hydrological applications, including hydropower plant operation. However, hydrologists have not given these two variables the same amount of attention as peak discharge $(Q)$, which is often considered in different hydrological and other geophysical applications (e.g., Frantar and Hrvatin, 2005; Parajka et al., 2013; Salinas et al., 2013; Viglione et al., 2013).

Recently, more attention has been given to all three variables $(Q, V, D)$ of the flood waves by using multivariate flood risk analyses with copula functions (e.g., Bacova-Mitkova and Halmová, 2014; De Michele and Salvadori, 2003; Grimaldi and Serinaldi, 2006; Šraj et al., 2015; Zhang et al., 2014). To determine the flood event volume and duration, the baseflow must be separated from direct runoff. Likewise, determining the baseflow, which can give essential information (e.g., to the water resources managers operating the irrigation systems) is a significant issue in various hydrological analyses. Blume et al. (2007) classified the baseflow separation methods into three major groups, i.e. graphical methods, automated digital filters and analytical solutions to baseflow separation. Graphical methods are usually used when a limited amount of discharge data are analyzed (e.g., McNamara et al., 1997; Šraj et al., 2015). In contrast, digital filters can easily be used for larger datasets (e.g., Gaal et al., 2012). Although the drawbacks of these two frequently used methods include their lacking physical basis (Blume et al., 2007; Furey and Gupta, 2001), these methods are easy to apply. A variety of automatic digital filters with one, two or three parameters are available (e.g., Chapman, 1991; Chapman, 1999; Eckhardt, 2005; Eckhardt, 2008; Gonzales et al., 2009; Nathan and McMahon, 1990).

After separating baseflow, several flood event elements can be defined (e.g., peak, volume and duration). These attributes can be used to conduct a detailed analysis of flood event elements and for analyzing the spatial relationships among numerous catchments according to the comparative hydrology concept (Falkenmark and Chapman, 1989; Gaal et al., 2012; Sivapalan, 2009). This concept aims to gain new knowledge from the spatial relationships between many catchments (and their behavior) rather than modeling one selected catchment in detail. A relatively large number of studies have been conducted for Austrian catchments, for which hydrological and meteorological data are available. Merz and Blöschl (2003) analyzed flood waves in Austria and identified five different types of flood events (long-rain floods, short-rain floods, rain on snow floods, snowmelt floods, and flash floods) using several process indicators (e.g., storm duration, catchment state, and the seasonality of floods). These authors found that more than 40 percent of floods in Austria are classified as long-rain floods and that the locations of the catchments play an important role in defining the dominant process type. Gaal et al. $(2011 ; 2012)$ analyzed factors that influence the flood timescale, which is defined as the ratio between the flood event volume and the flood peak. Again, the location of the station (lowland or hilly catchments) played an important role in the flood timescale characteristics. Furthermore, Gaal et al. (2012) found that the flood timescale values depend on the meteorological conditions (the predominant storm type), geological conditions and the antecedent soil moisture state of the catchment. However, the catchment area was not one of the most important factors. In addition, similar analyses were performed in other regions of the world (e.g., in the eastern region of the USA, Sawicz et al. (2011)). The aforementioned concept was also used for predictions in ungauged basins, namely runoff-hydrograph studies (Parajka et al., 2013), flood and low-flow studies (Salinas et al., 2013) and runoff signature analyses in Austria (Viglione et al., 2013).

The main objective of this study was to understand the factors that control the behavior and characteristics of flood events by using the concept of comparative hydrology. The specific aims of this study included the following: (i) identification of flood events and evaluation of their attributes for 50 Slovenian catchments; (ii) regionalization and crosscomparison of catchments; (iii) assessment of dependence among flood peak, volume and duration, catchments characteristics and process indicators. 


\section{DATA}

Daily discharge data measured by the Slovenian Environment Agency (ARSO, 2014) were used in this study. Fig. 1 shows the locations of the selected gauging stations in a topography map of Slovenia, where the elevation ranges from 0 to $2,864 \mathrm{~m}$ a.s.l. Some basic geographical characteristics of the analyzed stations based on the five major river basins (i.e., the Drava, Mura, Sava, Soča, and Adriatic rivers) are presented in Table 1. Overall, more than 2,500 flood events, which were selected based on daily discharge data from 50 Slovenian gauging stations, were analyzed. The annual precipitation in Slovenia spreads from less than $900 \mathrm{~mm}$ in the eastern part of Slovenia to more than $3,000 \mathrm{~mm}$ in the western part, which is more mountainous (Fig. 1).

Frantar and Hrvatin (2005) classified several Slovenian streams into five water regimes, the Alpine nival-pluvial regime (Drava; Mura; Sava, Soča and Savinja in the upper parts of the basin), Alpine pluvial-nival regime (Sava, Soča and Savinja in the downstream parts of the catchment), Dinaric pluvial-nival regime (Kolpa; Krka and some rivers that flow in a karst area, such as Ljubljanica), Panonian pluvial-nival regime (some smaller rivers in the north-eastern lowland portion of the country) and Mediterranean pluvial regime (most of the Adriatic rivers). However, not all stations considered in our study were included in the classification process that was performed by Frantar and Hrvatin (2005). Nevertheless, the previously mentioned groupings of water stations were mainly used for flow regime classification in Slovenia. The catchments in the aforementioned study were grouped (regionalized) using the Ward method of hierarchical clustering (Ward, 1963).
Table 1. Basic geographical characteristics of the considered gauging stations grouped into five river basins.

\begin{tabular}{lcccc}
\hline Basin & $\begin{array}{c}\text { Number of } \\
\text { stations }\end{array}$ & $\begin{array}{c}\text { Mean catch- } \\
\text { ment area } \\
{\left[\mathrm{km}^{2}\right]}\end{array}$ & $\begin{array}{c}\text { Mean } \\
\text { station } \\
\text { elevation }[\mathrm{m} \\
\text { a.s.1.] }\end{array}$ & $\begin{array}{c}\text { Mean AM } \\
\text { series } \\
\text { length } \\
\text { [years] }\end{array}$ \\
\hline Drava & 3 & 392 & 287 & 60 \\
Mura & 4 & 5267 & 189 & 58 \\
Sava & 28 & 773 & 333 & 66 \\
Soča & 13 & 351 & 213 & 61 \\
$\begin{array}{l}\text { Adriatic } \\
\text { rivers }\end{array}$ & 2 & 291 & 200 & 62 \\
\hline
\end{tabular}

\section{METHODS}

The corresponding flood events were extracted based on the annual maximum (AM) peak discharge (Q). Fig. 2 shows an example of the daily flow series and the estimated baseflow for the Gornja Radgona gauging station on the Mura River for 1949. In addition, Fig. 2 shows several flood event elements, including the peak discharge $(Q)$, flood event volume $(V)$, flood event duration $(D)$, and increasing and decreasing lines. The $\mathrm{R}$ package lfstat (Koffler and Laaha, 2012) was used for the baseflow separation. This package provides multiple functions that estimate several low-flow indices that are described in the World Meteorological Organization's manual for estimating and predicting low-flows (WMO, 2008). The baseflow separation algorithm of the lfstat package separates the discharge time series into blocks of five days. Next, the minimums of each fiveday period are determined and the turning points are identified

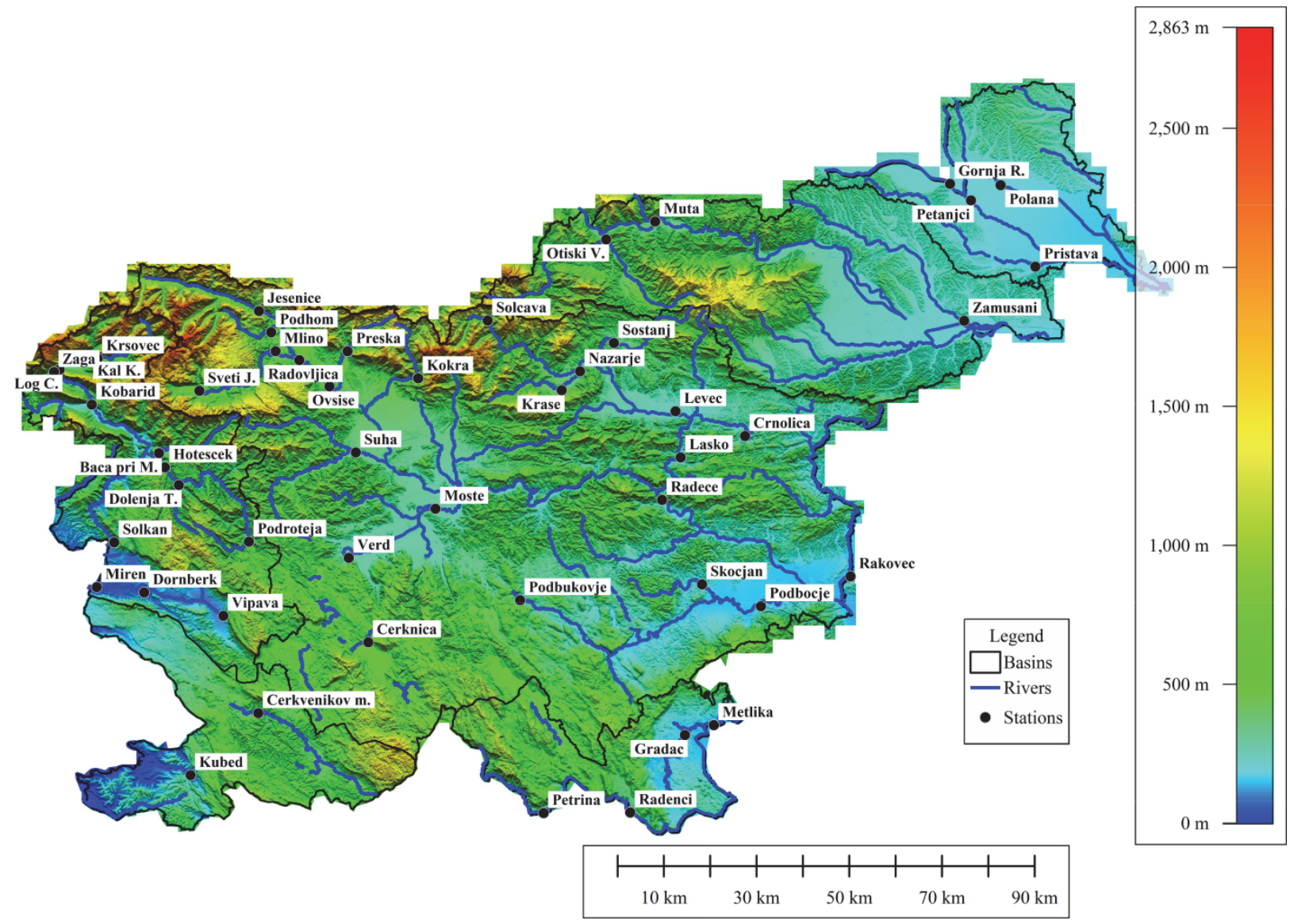

Fig. 1. Locations of the selected gauging stations on a digital elevation map of Slovenia. 

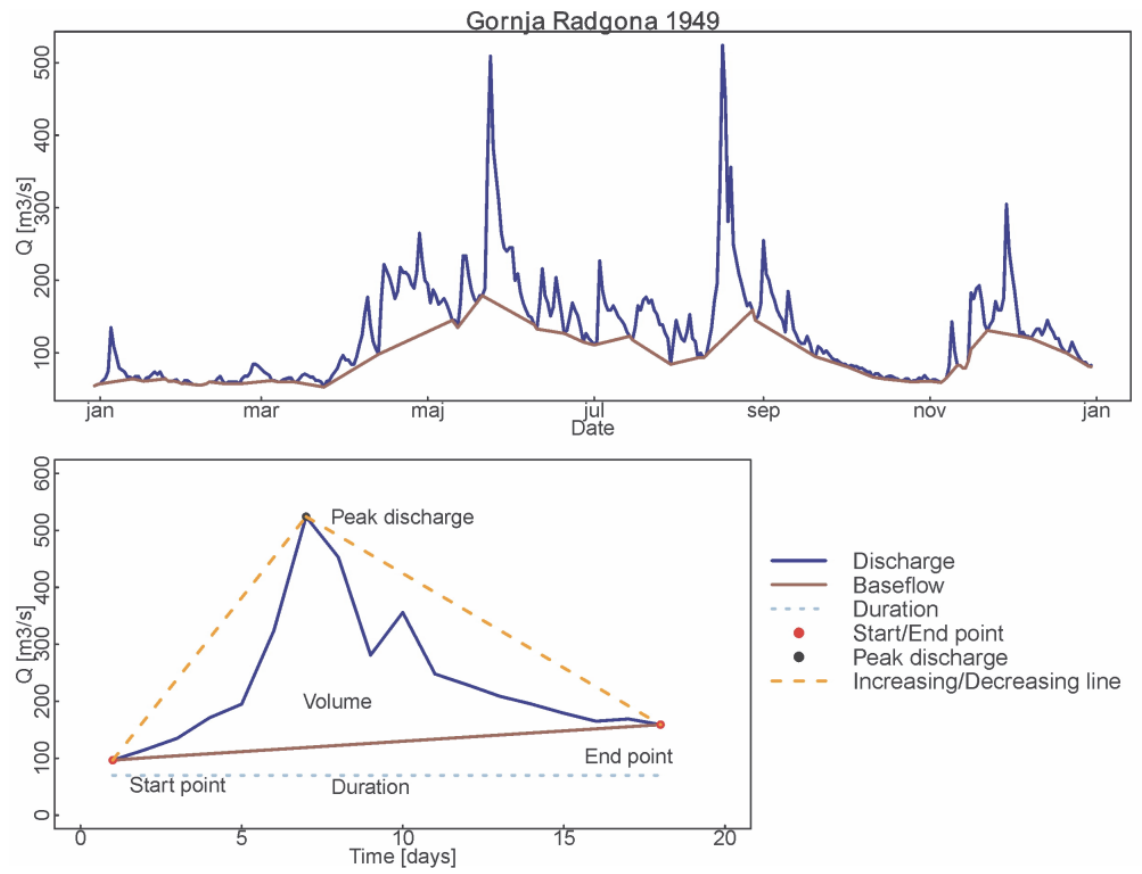

Fig. 2. Example of baseflow separation results from the Gornja Radgona station on the Mura River and a presentation of the flood event elements.

based on these minimums. The baseflow is defined based on the selected turning points (the start and the end points) and using linear interpolation between the turning points (Fig. 2).

Detailed description is given in the previously mentioned manual (WMO, 2008). The automatic baseflow separation algorithm was selected because more than 2,500 years of daily discharge data were analyzed in this study.

In order to group the catchments, the subjective grouping algorithm (Fig. 3), the K-means algorithm (e.g., Hosking and Wallis, 1997) and the Ward method (Ward, 1963) were tested. The thresholds (Fig. 3) for the subjective algorithm were selected using the so-called trial and error (subjective) method, where the objective was to classify stations into meaningful groups in terms of their geographical distributions.

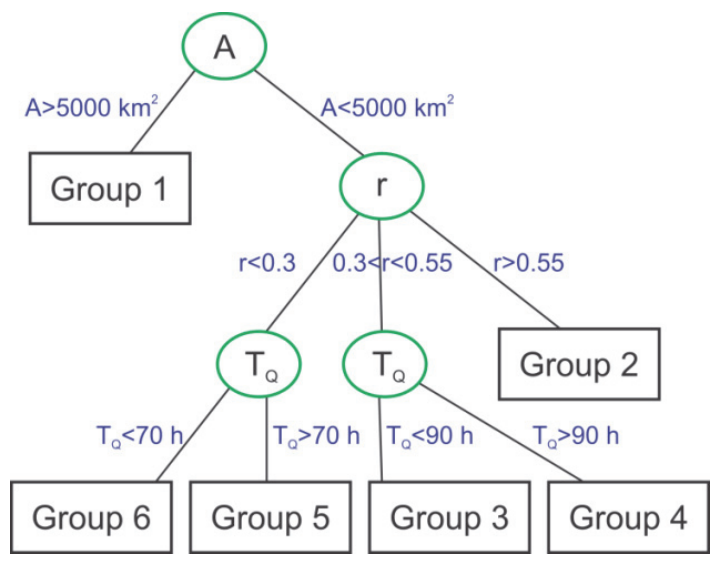

Fig. 3. Graphical presentation of the methodology used to group the gauging stations based on their catchment area $(A)$, coefficient of seasonality $(r)$ and flood timescale $\left(T_{Q}\right)$.

Several process indicators can be calculated based on the extracted flood event elements $(Q, V$ and $D)$. The flood timescale $\left(T_{Q}\right)$ [days or hours], which is the ratio between the flood event volume $(V)$ and peak discharge $(Q)$ (described by Bell and Kar
(1969)), was determined and is defined as follows (Gaal et al., 2012):

$T_{Q}=\frac{V}{Q}$,

where $V\left[\mathrm{~m}^{3}\right]$ is the flood event volume and $Q\left[\mathrm{~m}^{3} / \mathrm{s}\right]$ is the peak discharge. In addition, the slopes (gradients) of the increasing $k_{i}$ and decreasing $k_{d}$ lines [ $\mathrm{m}^{3} / \mathrm{s} *$ days], which are defined based on the starting point of the flood event, peak discharge point and end point of the flood event (Fig. 2), were calculated. Each slope was calculated from the coordinates of three aforementioned points. Two factors were defined based on the increasing slope $\left(k_{i}\right)$ and decreasing slope $\left(k_{d}\right)$, the specific increasing slope $\left(K_{i}\right)$ and the specific decreasing slope $\left(K_{d}\right)$ coefficients $\left[\left(\mathrm{m}^{3} / \mathrm{s} *\right.\right.$ days $\left.) / \mathrm{km}^{2}\right]$, which were calculated as follows:

$K_{i}=\frac{k_{i}}{A}$,

$K_{d}=\left|\frac{k_{d}}{A}\right|$,

where $A$ is the catchment area $\left[\mathrm{km}^{2}\right]$. For each of the analyzed flood events, we estimated the $k_{d}$ and $k_{i}$ values. Next, the median of these values was assessed for each station to obtain one $K_{d}$ and one $K_{i}$ value for each station based on the results from analyzing multiple flood events. These two factors are used to describe the flashiness (quick discharge increases and relatively quick decreases) of the stream, which can be observed from the flood events.

Flood seasonality can be expressed using circular statistics (Burn, 1997). Next, equations can be used to determine the coefficient of seasonality $(r)$ as follows:

$\theta=($ day no. -0.5$) \frac{2 \pi}{\text { year length }[\text { in days }]}$, 
$x=\cos \theta_{i} ; \quad y=\sin \theta_{i}$,

$\bar{x}=\frac{1}{n} \sum_{i=1}^{n} \cos \theta_{i} ; \quad \bar{y}=\frac{1}{n} \sum_{i=1}^{n} \sin \theta_{i}$,

$r=\sqrt{\bar{x}^{2}+\bar{y}^{2}}$,

where $\theta$ represents the timing of the selected event [-] and $r$ is the coefficient of flood seasonality [-], which also captures the climate characteristics of the analyzed catchment using a value of between 0 and 1 . If $r$ is near 0 , the seasonality is weak and almost none of the considered events occur at the same time of the year. In the opposite situation, namely if $r$ is closer to 1 , the seasonality is strong. The months of January, February and March were classified as winter, the months of April, May and June were classified as spring, the months of July, August and September were classified as summer, and the months of October, November and December were classified as autumn.

Spearman's and Pearson's correlation coefficients $(R)$ were selected as indicators of dependence among flood event elements, catchments characteristics and process indicators. The later coefficient is a measure of linear dependence; however the first one is based on ranks and can therefore also be used to measure other types of dependencies. Dependence was assessed among the factors that control the flashiness stream described using two coefficients $K_{i}$ and $K_{d}$ and several geographical characteristics of the catchments, including the Gauss-Krüger $X$ coordinate $(G K X)$, Gauss-Krüger $Y$ coordinate $(G K Y)$, catchment area $(A)$, and mean annual precipitation $(P)$. Furthermore, connection among pairs of variables that define flood events $(Q$, $V, D)$ and geographical catchment characteristics was also investigated.

\section{RESULTS \\ Identification of flood events}

The first step of the analysis was to separate the baseflow from more than 2,500 years of daily discharge data collected from Slovenian streams. After baseflow separation, several flood events were selected based on the AM peak discharge for detailed analyses. More than 2,500 flood events from 50 Slovenian catchments were extracted and basic elements were determined for each of the flood events, as shown in Fig. 2.

\section{Grouping and cross-comparison of catchments}

In the next step, the catchments were divided into groups based on their selected indices where several grouping algorithms were tested (subjective method, K-means algorithm and Ward method). Fig. 3 shows a graphical presentation of the chosen subjective methodology for dividing the gauging stations into homogeneous groups. The catchment area $(A)$, coefficient of seasonality $(r)$ (defined in Eq. 4) and the flood timescale $\left(T_{Q}\right)$ (described in Eq. 1) were used as discriminative factors. For each of the considered stations, the median $T_{Q}, K_{i}$ and $K_{d}$ values were calculated based on $n$ extracted flood events, where $n$ is the number of AM years that differ from station to station. These three indices $\left(A, r\right.$ and $\left.T_{Q}\right)$ were selected because they were not considered in existing studies that address the flow regimes of the Slovenian rivers (e.g., Frantar and Hrvatin, 2005). The K-means algorithm (e.g., Hosking and Wallis, 1997) and Ward method (Ward, 1963) did not provide logical geographical division of the stations into groups. Therefore the subjective algorithm (Fig. 3) was applied further in this study. The results of grouping the catchments using the aforementioned methodology are presented in Fig. 4.

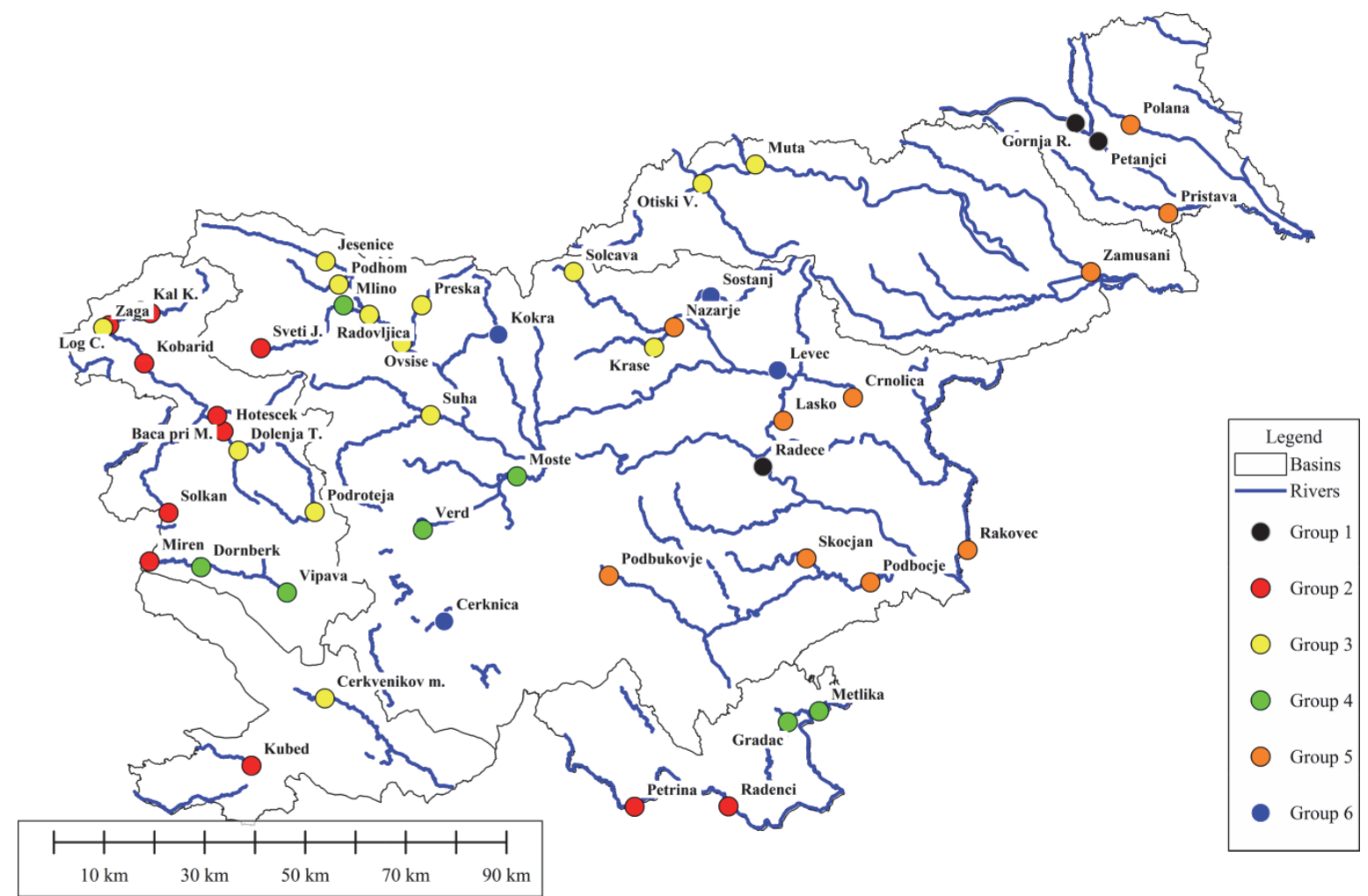

Fig. 4. Division of the analyzed gauging stations into six groups based on the presented methodology. 

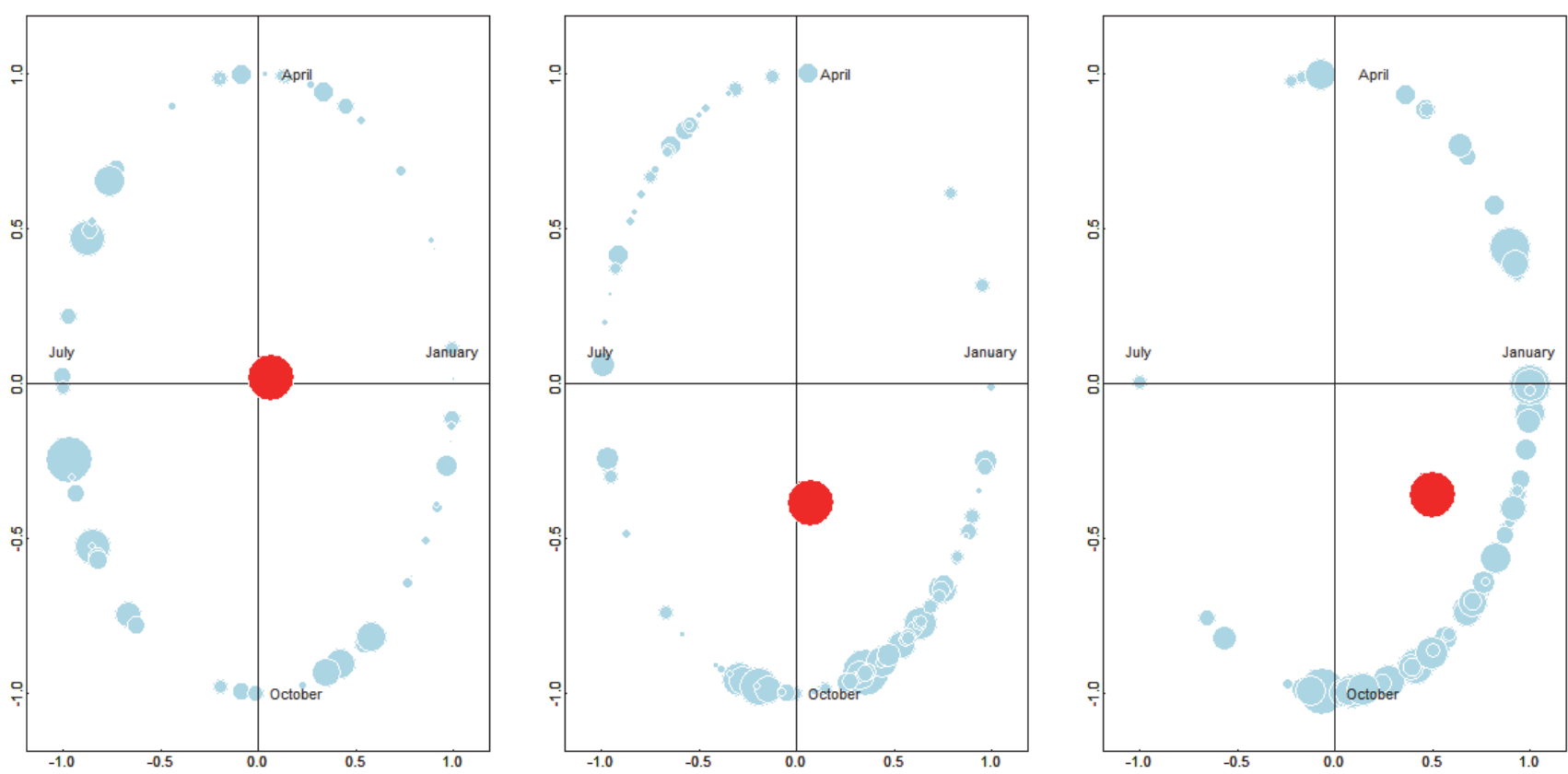

Fig. 5. Presentation of the flood seasonality characteristics with the coefficient of seasonality $r$ for three stations, the Polana station on the Ledava River (left), the Jesenice station on the Sava River (middle) and the Bača pri Modreju station on the Bača River (right), where the bubble size indicates the magnitude of the flood event.

Table 2. Mean values of the coefficients of seasonality $(r)$, timing of the AM events $(\theta)$, flood timescale $\left(T_{Q}\right)$, specific increasing slope $\left(K_{i}\right)$ and specific decreasing slope $\left(K_{d}\right)$ for the six predefined groups.

\begin{tabular}{lcccccc}
\hline Group & 1 & 2 & 3 & 4 & 5 & 6 \\
\hline Mean $r[-]$ & 0.467 & 0.605 & 0.454 & 0.466 & 0.196 & 0.22 \\
Mean $\theta[-]$ & 250 & 322 & 308 & 332 & 208 & 295 \\
Mean $T_{Q}[\mathrm{~h}]$ & 86 & 87 & 72 & 102 & 98 & 60 \\
Mean $K_{i}$ & & & & & & \\
{$\left[\left(\mathrm{~m}^{3} / \mathrm{s}^{*}\right.\right.$ days $\left.) / \mathrm{km}^{2}\right]$} & 0.017 & 0.117 & 0.111 & 0.057 & 0.035 & 0.082 \\
Mean $K_{d}$ & & & & & & \\
{$\left[\left(\mathrm{~m}^{3} / \mathrm{s}^{*}\right.\right.$ days $\left.) / \mathrm{km}^{2}\right]$} & 0.005 & 0.036 & 0.029 & 0.018 & 0.012 & 0.020 \\
\hline
\end{tabular}

Despite the absence of geographical catchment characteristics in the grouping procedure, such as the locations of the stations, the spatial coherence of several groups were observed. However, this result was one aim of using the grouping procedure. The catchments with relatively strong seasonality are mainly located in the western regions of the country (group 2). In contrast, most of the stations in the eastern regions have relatively weak seasonality and significantly larger flood timescales (group 5). Medium seasonality is characteristic of most of the stations in the northern and central portions of Slovenia (groups 3 and 4). However, only 3 and 4 stations were classified into groups 1 and 6 , respectively. The mean values of the coefficient of seasonality $(r)$, timing of seasonality $(\theta)$, flood timescale $\left(T_{Q}\right)$, specific increasing slope $\left(K_{i}\right)$ and specific decreasing slope $\left(K_{d}\right)$ for each of the groups were computed based on the median $T_{Q}$, $K_{i}$ and $K_{d}$ values from each gauging station. These results are presented in Table 2. Regarding seasonality (mean $r$ ), group 1 is similar to groups 3 and 4 .

Fig. 5 shows the flood seasonality of three stations with different seasonality characteristics. The Polana station on the Ledava River, the Jesenice station on the Sava River $(r=0.39)$ and the Bača pri Modreju station on the Bača River $(r=0.62)$ are presented. These three stations are located in different regions of the country and have diverse seasonality characteristics. Hydrographs from these stations were variable and they were connected with the flood timescale parameter $T_{Q}$, which is characteristic of different groups. The analyzed flood events for one station from each of the six groups are presented in Fig. 6. For Fig. 6, flood events were selected from the following stations: Gornja Radgona on the Mura River (group 1), Bača pri Modreju on the Bača River (group 2), Jesenice on the Sava River (group 3), Moste on the Ljubljanica River (group 4), Podbočje on the Krka River (group 5) and Šoštanj on the Paka River (group 6).

\section{Dependence among flood characteristics, catchments attributes and process indicators}

The Pearson's correlation coefficient $(R)$ was calculated among the two coefficients that control the flashiness of the stream $(K i$ and $K d)$ and several geographical characteristics of the catchments, including the Gauss-Krüger $X$ coordinate $(G K X)$, Gauss-Krüger Y coordinate $(G K Y)$, catchment area $(A)$, and mean annual precipitation $(P)$. The dependence assessment and calculated Pearson's correlation coefficients for 50 Slovenian catchments, which were clustered into six groups, are presented in Fig. 7. For six stations, the mean annual precipitation was not defined because parts of these catchments were located in neighboring countries. Therefore, these stations were not included in this analysis. Likewise, the catchment area for the Verd station on the Ljubija River is unknown because the river flows through a karst area. This station is not shown in Fig. 7.

Table 3 shows the mean values of the calculated Spearman's correlation coefficients for pairs of variables $(Q, V, D)$ for all six predefined groups. The dependence between the pairs of variables is important in the multivariate flood frequency analysis using copula function approach. Based on this information different types of copulas (asymmetric or symmetric) can be selected to perform multivariate analysis. To determine which 

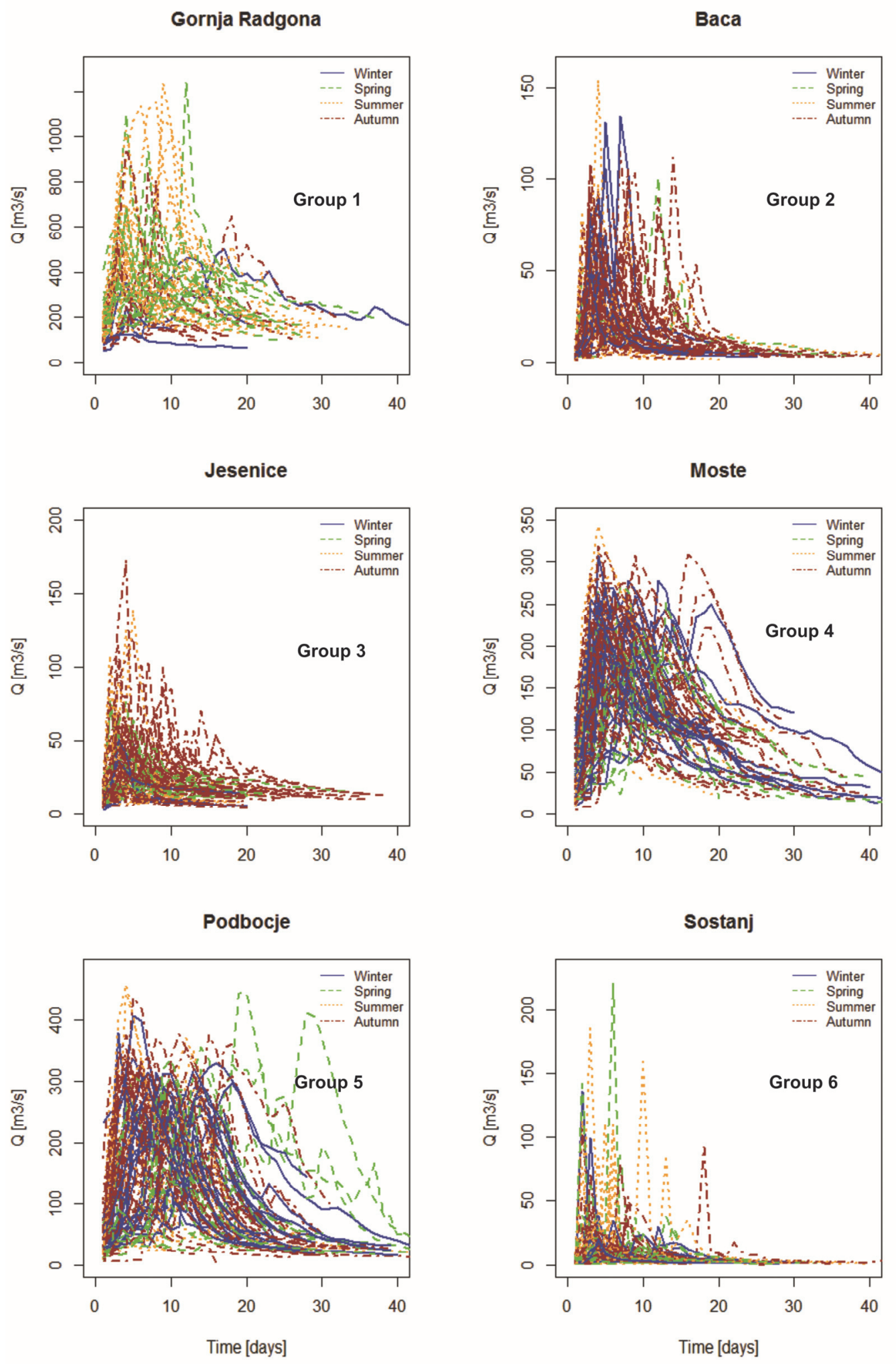

Fig. 6. Examples of analyzed flood events for one station of each of the six predefined groups.

process indicators control the relationships between pairs of variables $(Q-V ; V-D$ and $Q-D)$, a dependence assessment and the Pearson's correlation coefficient calculation $(R)$ among the calculated Spearman's correlation coefficients for the pairs of the three variables $(Q, V, D)$ and several geographical characteristics of the catchments, including $G K X, G K Y, A$ and
$P$, was conducted (Fig. 8). The clustering of catchments into groups was used as part of the dependence assessment. The idea behind the Fig. 8 is to show if the proposed subjective clustering algorithm identifies groups with different dependence characteristics and to stress out what is the connection between selected catchment attributes and flood event elements. 

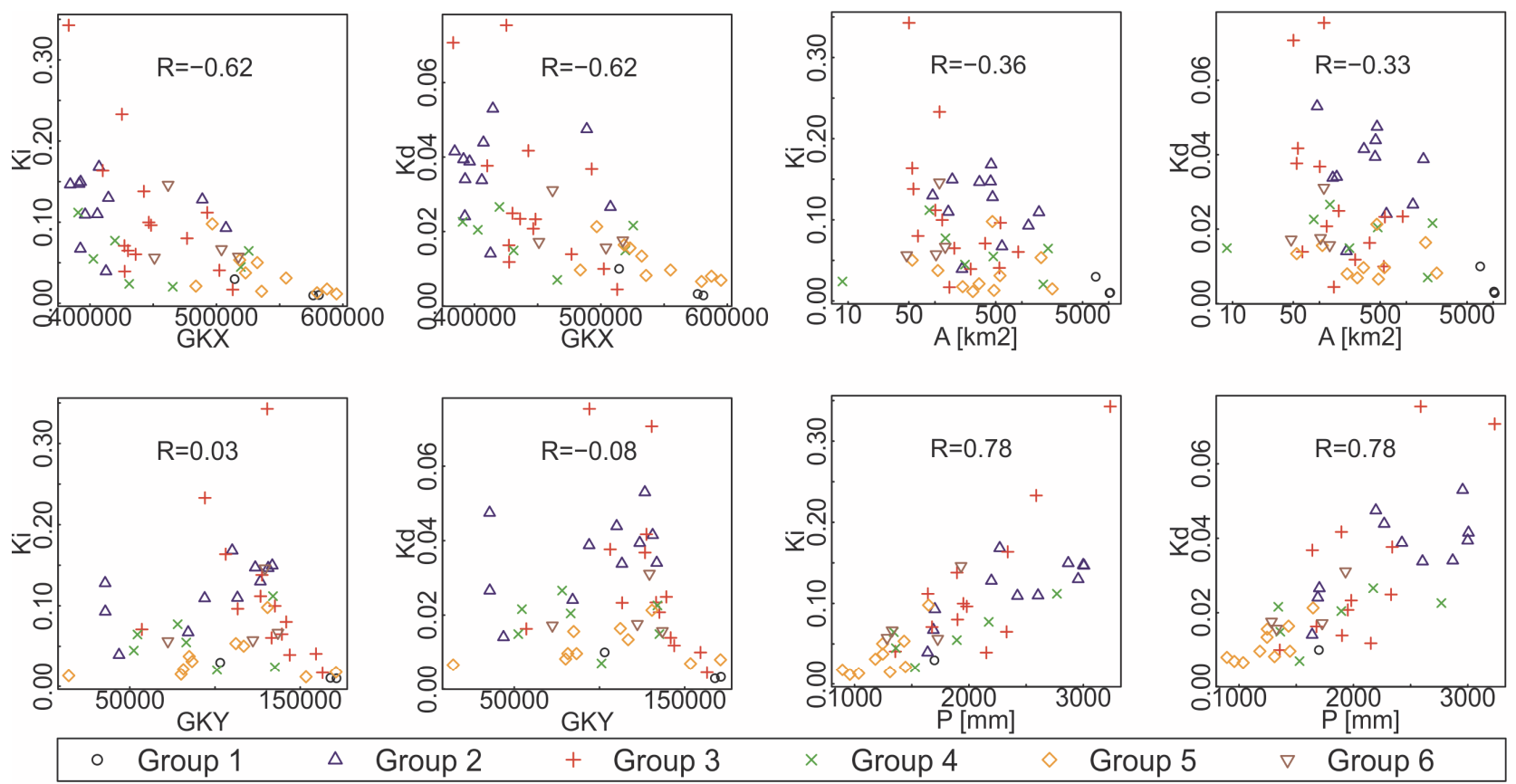

Fig. 7. Graphical presentation of the dependencies among the Gauss-Krüger $X$, Gauss-Krüger $Y, \log$ of the catchment area $A$, mean annual precipitation $P$ (rows of the matrix plot) and specific increasing and decreasing slopes ( $K_{i}$ and $K_{d}$, respectively) (columns of the matrix plot).

Table 3. Mean values of the Spearman's correlation coefficients between pairs of variables for six predefined groups, including the peak discharge $Q\left[\mathrm{~m}^{3} / \mathrm{s}\right]$, flood event volume $V\left[\mathrm{~m}^{3}\right]$ and flood event duration $D$ [days].

\begin{tabular}{lcccccc}
\hline Group & 1 & 2 & 3 & 4 & 5 & 6 \\
\hline$Q-V$ & 0.69 & 0.60 & 0.61 & 0.44 & 0.63 & 0.61 \\
$V-D$ & 0.64 & 0.46 & 0.50 & 0.55 & 0.45 & 0.39 \\
$Q-D$ & 0.19 & -0.01 & -0.03 & -0.05 & -0.02 & -0.12 \\
\hline
\end{tabular}

\section{DISCUSSION}

In this section, we discuss and explain the resulting groups of catchments in terms of climatic drivers (e.g., precipitation) and flood regimes. Furthermore, we investigated the relationships between the two coefficients that define the hydrograph shape $\left(K_{i}\right.$ and $\left.K_{d}\right)$ and some of the geographical attributes of the stations and evaluated the dependence characteristics between the pairs of variables that define the flood event $(Q, V$, and $D)$.

The coefficient of seasonality was selected as one of the factors in the grouping algorithm (Fig. 3). Fig. 5 shows three gauging stations that belong to different groups and are located in different regions of the country. Although all three stations have similar catchment areas, their flood characteristics differ significantly (Fig. 5). The Ledava River is classified as a Pannonian pluvial-nival river, which occurs in the plains of the Pannonian area (Frantar and Hrvatin, 2005). The early summer and late autumn peaks are characteristic of this regime and this is confirmed in Fig. 5. Consequently, the bimodality coefficient of seasonality for the peak discharges of the Polana station is small $(r=0.07)$. In contrast, the Sava River in Jesenice is classified as an Alpine nival-pluvial river, which includes rivers for which an important part of the catchment extends to the high mountains and where the effect of snow melt is very pronounced (Frantar and Hrvatin, 2005). The first peak in this regime typically occurs in late spring when the snow begins to melt, and the second peak generally occurs in October or November when maximum precipitation occurs. However, these results demonstrate (Fig. 5) that the autumn maximum is generally higher than the spring maximum in the Sava River at Jesenice. The resultant seasonality $(r=0.39)$ is consistent with this finding. The less pronounced spring peaks potentially resulted from the lack of snow precipitation in the Alps in recent decades (2000-2010) due to climate variability. Many researchers have reported decreasing snow depth in different parts of the Alps (Beniston, 2012; Hantel and Hirtl-Wielke, 2007; Schoner et al., 2009). In addition, Horvat et al. (2009) explored the snowmelt process in the Alps and its influence on the Sava River runoff and concluded that the snowmelt did not significantly affect the hydrological variables of the Sava River. Although the Bača River was not classified into any discharge regime by Frantar and Hrvatin (2005), it could be classified as a Dinaric pluvial-nival river, which is characteristic of the rivers in the Dinaric area with two fairly equalized peaks in the spring and autumn. The results of this study indicate that the autumn peak of the Bača station is more pronounced (Fig. 5) with more enhanced coefficient of seasonality $(r=0.62)$.

In addition, the flood timescale was used in the grouping procedure (Fig. 3). However, the timescale is closely related to the hydrograph shape (flood event). The results shown in Fig. 6 and Table 3 demonstrate that each group has different flood event elements. Relatively large flood event durations were observed in some flood events (up to 40 days; Fig. 6). These long event durations could be explained by more complex hydrograph shapes, which could result from snowmelt events, snow and rainfall events or long rainfall events (Merz and Blöschl, 2003). For stations in group 2, the seasonality is relatively explicit. However, in the presented example, most of the AM events occurred in the autumn or in the early spring (Fig. 5). Furthermore, the flood event durations were generally smaller than in some of the other groups. The stations in group 3 had similar characteristics as the stations in group 2. However, the value of $r$ was generally smaller, and the $D$ values were generally shorter. Thus, the majority of the AM events for the stations in 

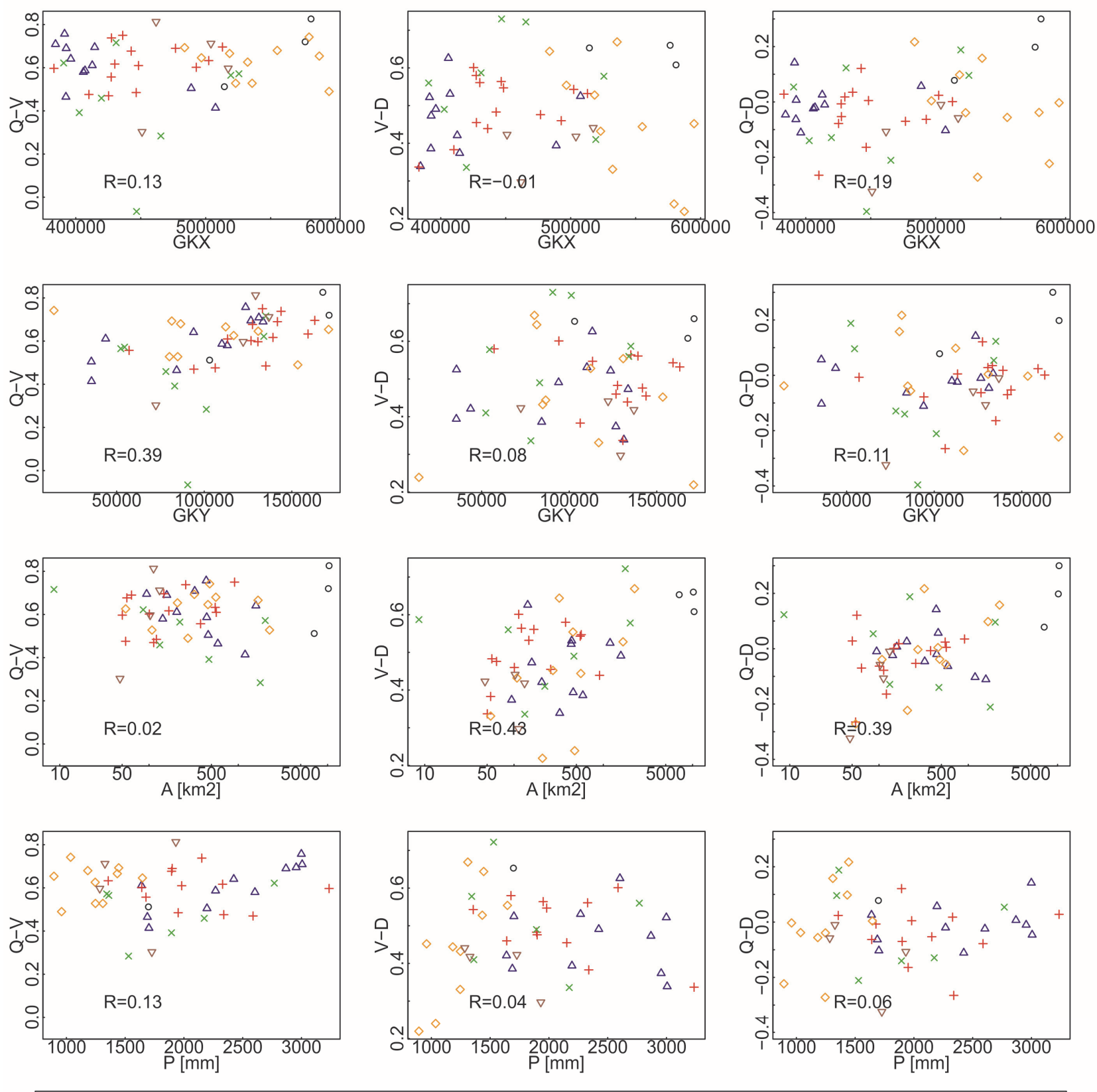

$\circ$ Group $1 \quad \triangle$ Group 2

+ Group 3

$\times$ Group 4

$\diamond$ Group $5 \quad \nabla$ Group 6

Fig. 8. Graphical presentation of the dependencies among the Gauss-Krüger $X$, Gauss-Krüger $Y, \log$ of the catchment area $A$, mean annual precipitation $P$ (rows of the matrix plot) and Spearman's correlation coefficients between the pairs of variables, peak discharge $(Q)$, flood event volume $(V)$ and flood event duration $(D)$ (columns of the matrix plot).

group 2 occurred in the same season. However, these results are not as explicit for the stations in group 3. For the stations in groups 4 and 5 more complex flood events were observed (Fig. 6) with longer flood event duration values. Again, the main difference between groups 4 and 5 is in the coefficient of seasonality. The seasonal pattern of the stations in these two groups is more complex. Similarly, for the stations in group 6 , the seasonality was not very significant. However, the flood events had a more explicit peak $(Q)$, which corresponded to shorter $D$ values (Fig. 6). The results in Fig. 6 demonstrate that the stations in groups 2, 3 and 6 have simpler flood event shapes than the gauging stations in the other three groups with mostly complex flood events. Therefore, the mean $K_{i}$ value is generally larger for catchments in groups 2, 3 and 6 than for stations in the other three groups. Furthermore, the mean $K_{d}$ value followed a pattern that was similar to that of the $K_{i}$ (Table 2). These two factors are indicators of the more flashy streams, which are characterized by the quick increase and relatively quick decrease in runoff. This finding corresponds with the topography map shown in Fig. 1, which shows that the catchment landscapes at the stations in groups 2, 3 and 6 are more mountainous than for other stations (Fig. 4). More complex flood events were observed for the stations in groups 1, 4 and 5. Consequently, the $K_{i}$ and $K_{d}$ values were generally smaller (Table 2). In addition, relatively high correlation coefficients were obtained among the $P$ and $G K X$ variables and the $K_{i}$ and 
$K_{d}$ values (Fig. 7). Furthermore, the different behaviors of the stations in the different groups could be observed from the dependence assessment plots in Fig. 7. The relationships between the rainfall $(P)$ and the east-west location of the stations $(G K X)$ were expected because the precipitation in Slovenia increases from the east to west (more mountainous) regions of the country. For the stations with smaller $K_{i}$ and $K_{d}$ values, less rainfall was observed. Obviously, the locations (east-west) of the stations influenced these two coefficients. Furthermore, the $K_{i}$ and $K_{d}$ values were significantly higher in the western part of the country. Lower Pearson's correlation coefficients were obtained for combinations of $G K Y, A$ and $K_{i}, K_{d}$ (Fig. 7). For these pairs of variables, fewer differences were observed between the six predefined groups, as shown in Fig. 7. Furthermore, some connection was observed between the catchment area $A$ and the $K_{i}$ and $K_{d}$ values. In addition, Gaal et al. (2012) analyzed the connection between $T_{Q}$ and $A$ for several catchments in Austria. These authors indicated that the calculated Pearson's correlation coefficient between the $T_{Q}$ and the logarithm of the catchment area was 0.45 (Gaal et al., 2012). However, a value of 0.34 was obtained in this study (Fig. 7). Geological map of Slovenia is relatively complex (Bavec et al., 2013), however if few simplifications are made two major geological types can be identified. Limestone and dolomite are predominant rocks in the west, the south, the south-east and partly the north part of Slovenia. Furthermore, in the northeastern, central and partly eastern part of Slovenia clastic sediments are predominant. One can notice that more significant seasonality $(r)$ is characteristic of dolomite and limestone catchments (e.g., Groups 2 and 3), but the opposite can be said for clastic sediment catchments (e.g., Group 5). Likewise, the precipitation distribution in Slovenia is also west-east oriented, meaning that higher annual precipitation values are observed in western part of the country where dolomite and limestone catchments are dominant, and smaller precipitation amounts are measured in the eastern part of Slovenia where clastic sediment catchments are mainly located. Due to the complex topography and climate conditions short-term intense convective storms (thunderstorms) are more frequent in western part of the country, especially in summer. This also explains larger $K_{i}$ and $K_{d}$ values for catchments in Groups 2, 3 and 6, which indicates more flashy stream behavior. The opposite results were conducted for catchments located in the eastern part of the country where frontal precipitations are dominant through the year.

Conducting a dependence assessment between the pairs of variables that define the flood event, namely the $Q, V$, and $D$ variables, is an important step when using the multivariate frequency analysis approach (e.g., Grimaldi and Serinaldi, 2006; Sraj et al., 2015). Based on the dependence assessment results, the symmetric or asymmetric copula functions could be selected for analysis (e.g., Grimaldi and Serinaldi, 2006; Šraj et al., 2015). Symmetric copulas are more appropriate when the dependence between the pairs of variables is similar. However, the asymmetric copula version is more useful when the dependencies are not similar. When studying Austrian catchments, Gaal et al. (2014) found that the Spearman's correlation coefficients between the $Q$ and $V$ values were between 0.2 and 0.8 , which correspond with the findings presented in this study (Fig. 8). Furthermore, the dependence between $Q$ and $V$ was generally more explicit for the lowland Austrian catchments than for the Austrian alpine catchments (Gaal et al., 2014). In contrast, the Spearman's correlation coefficients for the $Q-V$ pair are generally larger for streams located in more mountainous areas in Slovenia than in lowland catchments. However, these differences between lowland and mountainous catchments were not signifi- cant. These differences could be attributed to the selected baseflow separation algorithm, which could result in differences when considering mixed flood events (snow and rain combination). In addition, more data are available from high alpine catchments in Austria; thus, some catchments could be classified as mountainous in Slovenia, but not in Austria. Furthermore, different results obtained in terms of the dependencies could occur if more than 1 event per year was selected for analysis (e.g., the peaks over threshold method). From Fig. 8, it can be observed that the calculated dependences among the Spearman's correlation coefficients and the $G K X, G K Y, P$ and $A$ values are relatively weak. To some degree, the dependencies between $A$ and $V-D, A$ and $Q-D$, and GKY and $Q-V$ can be observed (Fig. 8). This result indicates that no generalization is possible when defining the dependencies between the flood event elements $(Q, V$ and $D)$ based on the location of the station (south-north and east-west), the catchment area and the mean annual precipitation. Likewise, it was not possible to determine a connection between the pairs of variables $(Q-V, V-D$ and $Q-D)$ using the proposed grouping algorithm. Stations in the same group generally do not have the same dependency characteristics. Gaal et al. (2014) found that climate related factors have more influence on peak discharges $(Q)$ and flood event volumes $(V)$ relationship than the catchment related factors. In our study the relationship between mean annual precipitation and flood event elements is generally weaker than dependence between some of the catchment attributes and flood event elements (Fig. 8). However, this finding is more significant for pairs of variables $V-D$ and $Q-D$, which were not considered in the study conducted by Gaal et al. (2014). For nearly all of the stations, the mean correlations between $Q-V$ were larger than between $V$ $D$. However, the only exception is group 4 , which mainly consists of the stations from the Karst rivers. The smallest correlation (or almost no correlation) was observed between $Q-D$. Furthermore, this correlation was negative except for stations in group 1. This exception could be attributed to the large catchment area of the stations in this group $\left(\mathrm{A}>5000 \mathrm{~km}^{2}\right)$. These results indicate that the dependence characteristics between the pairs of variables for the Slovenian stream are not similar. Thus, in terms of multivariate flood frequency analysis, asymmetric copulas should function better than the symmetric versions of copulas. Grimaldi and Serinaldi (2006) showed that the correlations between different flood event elements depend on the selected discharge threshold for baseflow separation. Furthermore, these authors observed that the correlation between $Q-D$ was generally smaller than the correlation between $Q-V$ and $V$ $D$. For the Litija station on the Sava River, which was not considered in this study, Šraj et al. (2015) discovered that the correlation between $V$ and $D$ was larger than that between $Q$ and $V$. However, Šraj et al. (2015) used graphical method for baseflow separation.

\section{CONCLUSIONS}

This paper presents a detailed analysis of several flood event elements. Overall, more than 2,500 flood events, which were selected based on the AM peak discharges, were analyzed from 50 Slovenian gauging stations. After baseflow separation, which was performed using an automatic digital filter implemented in the $\mathrm{R}$ package lfstat, the stations were divided into six groups based on the catchment area $(A)$, seasonality coefficient $(r)$ and flood timescales $\left(T_{Q}\right)$ values (Figs 3 and 4 ).

Different types of flood events were characteristic of the different predefined groups (Fig. 4). For the stations in groups 2, 3 and 6 , a greater number of simple flood events with relatively 
quick runoff increases and decreases were observed. However, the characteristics of the catchments in the other groups included more complex flood events that yield higher $D$ values, larger $T_{Q}$ values, and smaller $K_{i}$ and $K_{d}$ values (Table 2). The $K_{i}$ and $K_{d}$ values control the flashiness of the stream (quick runoff increases and decreases). Although no geographical catchment attributes were considered in the classification process (Fig. 3 and Fig. 4), the predefined groups were dependent on the Gauss-Krüger $X(G K X)$ coordinate, which was one aim of the classification process (to obtain a logical geographical distribution of the stations). In addition, the predefined groups were dependent on the mean annual precipitation $(P)$, which is connected with the $G K X$ (Fig. 7). The predominant geological type for catchments in Groups 2 and 3 is limestone and dolomite; however catchments on clastic sediments are mostly located in the eastern part of Slovenia (Group 5). Furthermore, some level of dependence was observed for the pairs of $G K X-K_{i}, G K X-K_{d}$, $P-K_{i}$ and $P-K_{d}$, and a connection was observed between the two hydrograph coefficients $\left(K_{i}\right.$ and $\left.K_{d}\right)$ and the catchment area $A$ (Fig. 7).

The dependence for the $Q-V$ pair was generally larger than the connection between the $V$ and $D$ values. However, exceptions occurred for some of the stations on the rivers, which flow through the Karst. The smallest correlation (almost no correlation) was observed between the $Q-D$ variables. The calculated Pearson's correlation coefficients were relatively large between the catchment area and the $V$ and $D$ values and the catchment area and the $Q$ and $D$ values, respectively. Furthermore, dependencies between the north-south location $(G K Y)$ of the stations and the $Q$ and $V$ values (Fig. 8) were observed. However, for the other combinations shown in Fig. 8, weaker dependences were observed. These results indicate that the dependencies between the pairs of variables are not similar. Thus, when using the multivariate flood frequency analysis approach, asymmetric copulas should have some advantage before the symmetric versions of the copula functions. Furthermore, no generalization regarding the dependency between the pairs of variables can be made based on the predefined groups (Fig. 4).

Acknowledgements. We wish to thank the Environmental Agency of the Republic of Slovenia (ARSO) for providing the data used in this study. The results of the study are part of the Slovenian national research project J2-4096, which is financed by the Slovenian Research Agency (ARRS). In addition, this study was financed through the P2-0180 Water science and technology, and Geotechnics research program. The authors are grateful to two anonymous reviewers and the associate editor for providing critical and useful comments that were used to improve this work.

\section{REFERENCES}

ARSO, 2014. http://vode.arso.gov.si/hidarhiv/pov_arhiv_tab.php Accessed: 1.2.2014

Bacova-Mitkova, V., Halmová, D. 2014. Joint modeling of flood peak discharges, volume and duration: a case study of the Danube River in Bratislava. Journal of Hydrology and Hydromechanics, 62, 186-196.

Bavec, M., Novak, M., Poljak, M. 2013. Geological Map of Slovenia 1: 1.000.000. Geological Survey of SloveniaGeoZS. Accessed: 15.12.2014. http://www.geozs.si/UserFiles/677/File/Monograf_PDF/OGE_knjiznica.pdf.

Bell, F.C., Kar, S.O., 1969. Characteristics response times in design flood estimation. Journal of Hydrology, 8, 173-196.
Beniston, M., 2012. Is snow in the Alps receding or disappearing? Wiley Interdisciplinary Reviews-Climate Change, 3, 349-358.

Blume, T., Zehe, E., Bronstert, A., 2007. Rainfall-runoff response, event-based runoff coefficients and hydrograph separation. Hydrological Sciences Journal-Journal Des Sciences Hydrologiques, 52, 843-862.

Burn, D.H., 1997. Catchment similarity for regional flood frequency analysis using seasonality measures. Journal of Hydrology, 202, 212-230.

Chapman, T., 1999. A comparison of algorithms for stream flow recession and baseflow separation. Hydrological Processes, 13, 701-714.

Chapman, T.G., 1991. Evaluation of automated techniques for base flow and recession analyses - comment. Water Resources Research, 27, 1783-1784.

De Michele, C., Salvadori, G., 2003. A Generalized Pareto intensity-duration model of storm rainfall exploiting 2Copulas. Journal of Geophysical Research-Atmospheres, 108(D2).

Eckhardt, K., 2005. How to construct recursive digital filters for baseflow separation. Hydrological Processes, 19, 507-515.

Eckhardt, K., 2008. A comparison of baseflow indices, which were calculated with seven different baseflow separation methods. Journal of Hydrology, 352, 168-173.

Falkenmark, M., Chapman, T.G., 1989. Comparative hydrology: an ecological approach to land and water resources. Paris: Unesco.

Frantar, P., Hrvatin, M., 2005. Pretocni rezimi v Sloveniji med letoma 1971 in 2000. [Discharge regimes in Slovenia from 1971 to 2000]. Geografski vestnik, 77, 115-127. (In Slovenian.)

Furey, P.R., Gupta, V.K., 2001. A physically based filter for separating base flow from streamflow time series. Water Resources Research, 37, 2709-2722.

Gaal, L., Bloeschl, G., Szolgay, J., Karabova, B., Valent, P., Parajka, J., 2011. Regional analysis of peak-volume relationships of floods in Austria - time scales and correlations. Geophysical Research Abstracts, Vol. 13, EGU2011-10722.

Gaal, L., Szolgay, J., Kohnova, S., Parajka, J., Merz, R., Viglione, A., Bloeschl, G., 2012. Flood timescales: Understanding the interplay of climate and catchment processes through comparative hydrology. Water Resources Research, 48, doi: 10.1029/2011WR011509.

Gaal, L., Szolgay, J., Kohnova, S., Hlačova, K., Parajka, J., Viglione, A. Merz, R., , Bloeschl, G., 2014. Dependence between flood peaks and volumes - A case study on climate and hydrological controls. Hydrological Sciences Journal, doi: 10.1080/02626667.2014.951361.

Gonzales, A.L., Nonner, J., Heijkers, J., Uhlenbrook, S., 2009. Comparison of different base flow separation methods in a lowland catchment. Hydrology and Earth System Sciences, 13, 2055-2068.

Grimaldi, S., Serinaldi, F., 2006. Asymmetric copula in multivariate flood frequency analysis. Advances in Water Resources, 29, 1155-1167.

Hantel, M., Hirtl-Wielke, L.M., 2007. Sensitivity of Alpine snow cover to European temperature. International Journal of Climatology, 27, 1265-1275.

Horvat, A., 2009. Vloga snega $v$ hidroloskem krogu na porecje Save : magistrsko delo. [The role of snow in the hydrological cycle on the Sava River basin]. MSc Thesis. A. Horvat, Ljubljana. (In Slovenian.) 
Hosking, J.R.M., Wallis, J.R., 1997. Regional Frequency Analysis: an Approach Based on L-moments. Cambridge University Press, Cambridge.

Koffler, D., Laaha, G., 2012. LFSTAT - an R-package for lowflow analysis. Geophysical Research Abstracts, Vol. 14, EGU General Assembly, Vienna, 22-27.4.2012.

McNamara, J.P., Kane, D.L., Hinzman, L.D., 1997. Hydrograph separations in an Arctic watershed using mixing model and graphical techniques. Water Resources Research, 33, $1707-$ 1719.

Merz, R., Blöschl, G., 2003. A process typology of regional floods. Water Resources Research, 39, doi: 10.1029/2002WR001952.

Nathan, R.J., McMahon, T.A., 1990. Evaluation of automated techniques for base flow and recession analyses. Water Resources Research, 26, 1465-1473.

Parajka, J., Viglione, A., Rogger, M., Salinas, J.L., Sivapalan, M., Bloeschl, G., 2013. Comparative assessment of predictions in ungauged basins - Part 1: Runoff-hydrograph studies. Hydrology and Earth System Sciences, 17, 1783-1795.

Salinas, J.L., Laaha, G., Rogger, M., Parajka, J., Viglione, A., Sivapalan, M., Bloeschl, G., 2013. Comparative assessment of predictions in ungauged basins - Part 2: Flood and low flow studies. Hydrology and Earth System Sciences, 17, 2637-2652.

Sawicz, K., Wagener, T., Sivapalan, M., Troch, P.A., Carrillo, G., 2011. Catchment classification: empirical analysis of hydrologic similarity based on catchment function in the eastern USA. Hydrology and Earth System Sciences, 15, 2895-2911.

Schoner, W., Auer, I., Bohm, R., 2009. Long term trend of snow depth at Sonnblick (Austrian Alps) and its relation to climate change. Hydrological Processes, 23, 1052-1063.

Sivapalan, M., 2009. The secret to 'doing better hydrological science': change the question! Hydrological Processes, 23, 1391-1396.

Šraj, M., Bezak, N., Brilly, M., 2015. Bivariate flood frequency analysis using the copula function: a case study of the Litija station on the Sava River. Hydrological Processes, 29, 225238, doi: 10.1002/hyp.10145.

Viglione, A., Parajka, J., Rogger, M., Salinas, J.L., Laaha, G., Sivapalan, M., Bloeschl, G., 2013. Comparative assessment of predictions in ungauged basins - Part 3: Runoff signatures in Austria. Hydrology and Earth System Sciences, 17, 22632279.

Ward, J.H., 1963. Hierarchical grouping to optimize an objective function. Journal of the American Statistical Association, 58, 236-244.

WMO, 2008. Manual on low-flow estimation and prediction. Geneva, Switzerland: World Meteorological Organization.

Zhang, J., Ding, Z., You, J., 2014. The joint probability distribution of runoff and sediment and its change characteristics with multi-time scales. Journal of Hydrology and Hydromechanics, 62, 218-225.

Received 2 September 2014 Accepted 22 December 2014

Note: Colour version of Figures can be found in the web version of this article. 